\title{
FLEXIBILITY AND PROJECT VALUE: INTERACTIONS AND MULTIPLE REAL OPTIONS
}

\author{
MIROSLAV ČULÍK \\ VŠB - Technical University of Ostrava \\ Sokolska trida 33 \\ Czech Republic \\ Phone: +420597322471 \\ Email: miroslav.culik@vsb.cz
}




\begin{abstract}
This paper is focused on a project valuation with embedded portfolio of real options including their interactions. Valuation is based on the criterion of Net Present Value on the simulation basis. Portfolio includes selected types of European-type real options: option to expand, contract, abandon and temporarily shut down and restart a project. Due to the fact, that in reality most of the managerial flexibility takes the form of portfolio of real options, selected types of options are valued not only individually, but also in combination. The paper is structured as follows: first, diffusion models for forecasting of output prices and variable costs are derived. Second, project value is estimated on the assumption, that no real options are present. Next, project value is calculated with the presence of selected European-type options; these options and their impact on project value are valued first in isolation and consequently in different combinations. Moreover, intrinsic value evolution of given real options with respect to the time of exercising is analysed. In the end, results are presented graphically; selected statistics and risk measures (Value at Risk, Expected Shortfall) of the NPV's distributions are calculated and commented.
\end{abstract}

\title{
KEYWORDS:
}

Real option, underlying asset, exercise price, intrinsic value, payoff function, simulation, Cholesky algorithm, density function, distribution function, Value at Risk, Expected shortfall.

JEL: G11, G13, G17, G31 


\section{Introduction}

Most traditional methods used to decide whether or not an investment project should be undertaken rely on discounted cash flow (DCF) methods. DCF methodologies are built on a simple relationship between present value and future value. According to this methodology, the value of the project is equal to its expected future cash flow discounted to the present value at the weighted average cost of capital (WACC). This relationship can be mathematically written as follows:

$$
N P V_{o}=\sum_{t=0}^{n} \frac{F C F_{t}}{(1+W A C C)^{t}} .
$$

The company's WACC is the most common rate used to discount future cash flow. It is also the minimal expected return of the project required by investor for a given level of risk. The Net Present Value (NPV), particular version of DCF, is the most well known method used in corporate decision-making analysis. The NPV rule is simple: invest immediately, if NPV is positive, otherwise reject the project.

Although the NPV has been prevalent method used in the last decades, it has several limitations.

The NPV rule is based on basis „now or never”; that is, the project requires a full commitment right now, i.e. invest now or never. This would not be a problem on projects following a predetermined plan, regardless of how events unfold. But it is not reality. Managers have to manage investments by changing subsequent plans and past decisions in response to changing market conditions. It this decision making process, some decisions have to be done after some uncertainties are resolved. These future decisions can be modelled as call or put options, which can be under some pre specific conditions exercised. For instance, management may have the right (but no obligation) expand the production, if the product is accepted more favourably than it was originally expected. On the other hand, if the market conditions evolve unfavourably, the production can be temporarily shut down (and later restarted), or the project can be contracted or even abandoned. These possible future actions (options) have value, which should be valued and added to the project value. Traditional DCF does not capture this value (it is sometimes called passive approach). Real option valuations recognizes, that the environment is 
dynamic and uncertain and that a great value of a project can be created by identifying and exercising future actions hidden in real options.

There are at least three areas, where traditional DCF comes up short versus option theory:

- Flexibility. Flexibility is the ability to defer, abandon, expand, contract, etc. a project. Because the NPV rule is defined as passive (or static), values these options at zero, while the real option approach would correctly allocate some project value into these future options.

- Contingency. This is a situation, when future investments are contingent on the success of today's investment. Managers can make investments today - even those with negative NVP to access future possibilities. Traditional budgeting models inadequately value these optioncreating investments.

- Volatility. Somewhat counter intuitively, investments with greater uncertainty have higher option value. In standard finance, higher volatility means higher risk, higher discount rate and lower present value. In option theory, higher volatility - because of asymmetric payoff schemes - leads to higher option value.

The aim of the paper is to value project value with embedded portfolio of real options. Valuation is based on the criterion of Net Present Value on the simulation basis. Due to the technique applied, all the real options are valued as options of European type. Moreover it is assumed, that input (variable costs) and output price are random variables and will be forecasted by employing derived diffusion models. In addition, there is positive correlation between these two variables and that is why Cholesky algorithm is applied.

The paper is structured as follows: first, diffusion models for forecasting of output prices and variable costs are derived. Second, project value is estimated on the assumption, that no real options are present. Next, project value is calculated with the presence of selected European-type options; these options and their impact on project value are valued first in isolation and consequently in different combinations. Moreover, intrinsic value evolution of given real options with respect to the time of exercising is analysed. In the end, results are presented graphically; selected statistics and risk measures (Value at Risk, Expected Shortfall) of the NPV's distributions are calculated and commented. 


\section{Real options theory}

\subsection{Real options - fundamentals}

Real options use options theory to evaluate physical or real assets, as opposed to financial assets. This modern area of finance is described by many authors, see for example Dixit and Pindick (1994), Howel (2001), Dluhošová (2006), Mun, (2006), etc.

An important point is that traditional DCF approach assumes a single decision pathway with fixed outcomes and all decisions are made at the beginning of the investment process without the ability to change past decisions or to make new ones. The real option approach considers multiple decision pathways as a consequence of high uncertainty coupled with management's flexibility in choosing the optimal strategies or options along the way when new information becomes available. That is, management has the option to make strategy corrections when the uncertainty becomes resolved and choose the best strategy. Traditional DCF assumes a single static decision, while real option theory assumes dynamic series of decisions, where management has the flexibility to revise and adapt past decisions in response to actual real conditions.

This flexibility can be modelled as put and call options. A call option on an asset gives the right (but no obligation) to acquire the underlying asset by paying a pre-specified (exercise) price on or before a given maturity. Similarly, put option gives the right to sell the underlying asset and receive the exercise price.

Projects valued with traditional DCF method often provide values that underestimate the true market value of the asset. This is because these methods are not able to value and capture the value of „hidden” real options. These options are valuable and create great part of total project value. The value of option or a portfolio of options is called, as in the case of financial options, option premium; added to the value of project can lead to the situation, where those projects can be started, which with using traditional DCF methods would be normally rejected.

\subsection{Underlying parameters driving real option value}

Framework for application of real options methodology is based on exact definition of basic parameters driving the option value. The basic ones are:

- Underlying asset - in the case of real option it is project cash flows or, gross project value $V_{t}$ (i.e. the present value of the subsequent cash flow discounted back to the time $t$ ). The 
higher the value of the underlying asset, the higher value of call option, in the case of put option, the opposite is true.

- Exercise price - it is equal mostly to the investment cost, which would have to be spent in the case of call option, in the case of put options it usually means saved investment cost or salvage (selling) asset price.

- Time to expiration - it is the time period, during which the option can be exercised. It is usually assumed that the possibility of the action can appear whenever during the life of the project, i.e. option can be exercised whenever during certain period (American option), if the opportunity can be exercised only at pre-specified time, then we deal with European option.

- Volatility of underlying asset - value of an option and the project is the higher; the higher is the risk of the underlying asset expressed in its price volatility. This feature refers both to call and put options, because the probability of option exercising is also higher. Risk parameter and its influence on the project value is the key difference if compared to the traditional rules. Whereas higher risk leads to lower project value (if traditional rules are used), then the opposite is true if option approach is applied.

- Risk free rate - the higher rate, the higher option value.

Table 1 summarizes and compares basic parameters of financial and real option.

Table 1: Basic parameters of financial and real option and their comparison.

\begin{tabular}{|l|l|}
\hline \multicolumn{1}{|c|}{ FINANCIAL OPTION } & \multicolumn{1}{c|}{ REAL OPTION } \\
\hline Value of underlying asset & Present value of subsequent cash flow \\
\hline Exercise price & Investment cost \\
\hline Time expiration of option & Life of project \\
\hline Underlying asset volatility & Project cash flow volatility \\
\hline Risk-free rate & Risk-free rate \\
\hline
\end{tabular}

\subsection{Categorisation of real options}

Real options can be primarily classified by the type of the flexibility they provide. The description of the most common real option types which will be consequently applied in the application part of the paper including intrinsic value function is the contents of the following Chapters 2.3.1 - 2.3.5. 


\subsubsection{Option to defer a project}

This type of option is formally a European call option. It enables managers temporarily to defer starting the project and profit from future information, which are over time resolved and were unknown at the outset of the decision. Managers defer the project with investment cost $I$, if project's NPV is higher (if deferred) compared to its immediate starting. In other words, the option to defer (or wait) can bee seen as a call option on the gross project value, $V$, with the exercise price equals to required investment cost $I$.

Function of intrinsic value option to defer a project, $I V_{t}^{D}$, can be formally written as follows,

$$
I V_{t}^{D}=\max \left[V_{0}-I_{0}, \frac{1}{(1+r)^{t}} \cdot\left(V_{t}-I_{t}\right)\right] \text {, }
$$

where $V_{t}$ is the gross project value, i.e. present value of subsequent cash flow discounted to the time $t$.

\subsubsection{Option to expand a project}

If the project has already been once undertaken, management have the possibility to make additional investment and expand the initial scale of the production by $x \%$ (i.e. by building additional production capacity), if it turns out, that the output is better accepted by the market then originally anticipated. In the option pricing terminology, firm has a call option on additional cash flow from extended part of project with exercise price equals to investment cost $I_{E, t}$, which has to be spent on building additional capacity.

This type of option can be defined either as a European (project can be expanded only at a pre-specified date in the future) or whenever during the life of the project (American option).

Function of intrinsic value option to exercise, $I V_{t}^{E}$, can be formally written in this way,

$$
I V_{t}^{E}=\max \left[x \cdot V_{t}-I_{E, t} ; 0\right]
$$

where $I_{E, t}$ is the investment cost for project expanding at time $t$ and $x$ is the scale expanding of the basic project. It is obvious from (2), that a firm has the option to maintain the basic scale of the production (i.e. receive the gross project value $V_{t}$ at no extra cost) or expand the production and receive the expanded project value by paying the additional cost whichever is higher. For the gross project value at time $t$ with the option to expand holds,

$$
V_{t}^{\text {Total }}=V_{t}^{\text {Base }}+\max \left[x \cdot V_{t}-I_{E, t} ; 0\right] .
$$




\subsubsection{Option to contract a project}

Analogous to the option to expand the project it is the option to contract a project. In this case, management has the option to contract the initial scale of the production by $y \%$, and sale a part of the project in the case if the conditions (for example if the product is not well received on the market) turned out to be less favourable than those expected at the beginning of the investment process. The option to contract thus can be seen as a put option on the part of the initial project and cash flow generated by this part, which can be contracted with exercise price equals to the saved investment cost $I_{C, t}$.

This type of option can be defined both as a European (project can be contracted only at a pre-specified date in the future) and as an American (contraction can be made whenever during the life of the project).

Function of intrinsic value option, $I V_{t}^{C}$ can be formally written as follows,

$$
I V_{t}^{C}=\max \left[I_{C, t}-y \cdot V_{t} ; 0\right]
$$

where $I_{C, t}$ is the investment cost which can be saved if the project is contracted at time $t$ and $y$ is the proportional part of the cash flow from contracted initial project $V_{t}$.

It is apparent from (4), that firm can maintain the initial scale of the project with gross value $V_{t}$ or contract a part of the project and receive (i.e. to save) a part of investment cost. Mathematically can be gross project value at time $t$ with the option to contract formulated as follows,

$$
V_{t}^{\text {Total }}=V_{t}^{\text {Base }}+\max \left[I_{C, t}-y \cdot V_{t} ; 0\right]
$$

\subsubsection{Option to abandon a project}

If the conditions turned out to be permanently unfavourable, management may have the option to abandon the project in exchange for its salvage (or sale) price, $A_{t}$, before its expected life. From the firm's point of view, management has a put option on the gross value of the project with exercise price equals to the salvage or resale value, which can be written as,

$$
I V_{t}^{A}=\max \left[A_{t}-V_{t} ; 0\right] .
$$


It is obvious from (6), that management can continue the operation or abandon the project if, at time $t$, the salvage or resale value is higher then the subsequent cash flow from continuing the project discounted back to the time $t$. Project value at time $t$ can be again formulated as follows,

$$
V_{t}^{A}=\max \left[A_{t} ; V_{t}\right]
$$

\subsubsection{Option to temporarily shut down and restart a project}

In the case the revenues $R e v$ in a given year is not sufficient to cover variable cost of the production, management may have the option to temporarily shut down the production (or simply not to operate). Thus, operation in a given year may be viewed as a call option on the production (i.e. revenues) by paying variable $\operatorname{cost} C_{\mathrm{var}, t}$ as the exercise price. In other words, management has the option to operate and obtain revenues in a given year (net of other fixed cost $C_{f i x, t}$ of the production) minus variable cost or to shut down the production and pay only fixed cost of the production. Intrinsic function can be written as follows,

$$
I V_{t}^{S D}=\max \left(\operatorname{Re} v_{t}-C_{\mathrm{var}, t}, 0\right)
$$

and free cash flow generated by the project in a given year of production,

$$
F C F_{t}^{S D}=\left[Q \cdot \max \left(\operatorname{Re} v_{t}-C_{\mathrm{var}, t_{t}}, 0\right)-D E P_{t}-C_{f i x, t}\right] \cdot(1-d)+D_{t}-\Delta W C_{t},
$$

where $Q$ is total output in a given year, $D E P$ is depreciation in year $t, d$ is tax rate and $\triangle W C$ is net change in working capital.

\subsection{Interaction among real options}

Above described managerial flexibility is often valued as individual real options (i.e. one type of option at a time). In reality, managerial flexibility is usually in the form of combination of options, which can be exercised at a given time. For example, manager can decide, if it is better to contract the scale of the production or even it is better to abandon the project.

Moreover, there exist the situations, where the management has more options, which can be exercised in a given order. Due to the fact, that real options have single underlying asset (project cash flow or gross project value) multiple real options can interact.

Interactions generally depend on the following factors:

- type of the options (put or call),

- the degree of separation of their exercise times, 
- relative degree of being "in the money, at the money or out of the money),

- sequential order of the options.

The underlying principle of this analysis is that the value of an option in the presence of other options may differ from its value in isolation. Alternatively, the combined value of two or more options in the presence of each other may differ from the alternative of evaluating each option separately and adding their results.

More details on the interaction and non aditivity of the option values can be found in Trigeorgis (1998), Trigeorgis (2000), Trigeorgis and Schwartz (2001), etc.

In this study, four different combinations of real option will be analyzed (expand + contract, expand + abandon, contract + abandon, expand + contract + abandon $)$. Moreover, it will be assumed that the combinations of real options can be exercised only in a given year.

Real option interaction and impact on the NPV distribution statistics and risk measures is analyzed in the application part of the paper in Chapter 3.4.4.

\section{Application}

\subsection{Goal of the application}

The goal of this application is to value the investment project on simulation basis with embedded portfolio of real options. As a main criterion for valuation, Net Present Value is applied on the simulation basis. Real options described in previous chapters are first valued in isolation and consequently as a portfolios of real options. Evolution of intrinsic values of selected options over time is analyzed; results are graphically presented and commented.

It is supposed that there are two random variables affecting project value and these will be modelled as stochastic variables (output price and variable cost of production); the other ones are supposed to be deterministic (depreciation, fixed cost of production, tax rate etc). For their modelling, geometric Brownian model is applied with continuous returns. Moreover, it is assumed that the price of output and variable cost are correlated.

Results of calculations are presented in the form of density functions and distribution functions. For analysing of the real options impact on the project value, criterions modus, 
median, standard deviation of project NPV distribution are calculated, $\mathrm{VaR}^{1}$ and Expected Shortfall ${ }^{2}$ measures are used.

\subsection{Problem description}

The objective of the study is to analyse the impact of the real options on investment decisionmaking of a firm operating in energy generating sector.

A firm is facing problem if to start the project in the electricity generation sector. The project expected life is 20 years with the total investment outlay 15000 currency units (c.u.). The maximum capacity of the electricity generated per year is $1000 \mathrm{kWh}$, annual depreciation is 750 c.u., fixed cost of production is 600 c.u. and tax rate $d$ is constant at the level $30 \%$. The project is financed by equity only; cost of equity $R_{E}$ is $10 \%$.

Due to the price and operational costs uncertainty, the management will be able to revise its operational strategy 5 years after project imitating. More precisely, the management will be able to expand, contract, abandon or temporarily shut down the production. The type of decision depends on the prevailing market condition in the given year. The parameters of the future actions are in the following Table 2.

Table 2: Formulation of the possible management actions

\begin{tabular}{|c|c|c|c|}
\hline $\begin{array}{c}\text { Action } \\
\text { (real option type) }\end{array}$ & Underlying asset & Exercise price & Intrinsic value \\
\hline Production expanding & $\begin{array}{l}\text { present value of the } \\
\text { additional cash flow } \\
\text { from expanded part of } \\
\text { the project, } x, \\
(x=20 \% \text { of the base } \\
\text { scale project })\end{array}$ & cost of expanding 2250 c.u. & $\max \left[x \cdot V_{t}-I_{E, t} ; 0\right]$ \\
\hline $\begin{array}{c}\text { Production } \\
\text { contracting }\end{array}$ & $\begin{array}{l}\text { additional cash flow } \\
\text { from contracted part } \\
\text { of the project, } y, \\
(y=30 \% \text { of the base } \\
\text { scale project }\end{array}$ & $\begin{array}{c}\text { sale price of the contracted } \\
\text { part of the project } 7000 \mathrm{c} . \mathrm{u} .\end{array}$ & $\max \left[I_{C, t}-y \cdot V_{t} ; 0\right]$ \\
\hline $\begin{array}{c}\text { Project abandonment } \\
\text { resale project value } \\
A=3000 \text { c.u. }\end{array}$ & $\begin{array}{c}\text { gross project value } V \\
\text { (present value of subsequent } \\
\text { cash flow }\end{array}$ & $\max \left[A_{t}-V_{t} ; 0\right]$ \\
\hline $\begin{array}{c}\text { Production shutting } \\
\text { down }\end{array}$ & $\begin{array}{c}\text { Revenues in given } \\
\text { year, Rev, }\end{array}$ & $\begin{array}{c}\text { variable cost of production } \\
\text { in a given year, } V C,\end{array}$ & $\max \left(\operatorname{Re} v_{t}-V C_{t}, 0\right)$, \\
\hline
\end{tabular}

\footnotetext{
${ }^{1}$ Value at Risk states the risk level, which is defined as a minimal predictable loss on a given probability level $\alpha$ (significance level) within a prespecified time period.

${ }^{2}$ Expected shortfall is the average of the worst $100(1-\alpha) \%$ of losses.
} 


\subsection{Price and variable costs modelling}

For simplicity it is supposed, that both electricity prices and variable cost of production follow geometric Brownian model, where the stochastic increment of the modelled variable can be described by this equation,

$$
d S=\mu \cdot S \cdot d t+\sigma \cdot S \cdot d z
$$

and the value of the variable in the next period is formulated as,

$$
S_{t+d t}=S_{t} \cdot \exp \left(\mu-\frac{\sigma^{2}}{2}\right) d t+\sigma \cdot d z
$$

Here, $\mu$ is annual return (drift rate), $S$ is stochastic variable, $\sigma$ is volatility of $S$ and $d z$ is specific Wiener process and holds, that

$$
d z=\tilde{z} \cdot \sqrt{d t},
$$

where $\tilde{z}$ is random variable from standard normal distribution $\mathrm{N}(0,1)$.

Moreover, sometimes it is necessary to take into account the correlation of the modelled variables (or the random factors $\tilde{z}$ ). One possible way is to generate the random variables in accordance with the Cholesky decomposition,

$$
\vec{z}^{T}=\vec{e}^{T} \cdot P,
$$

where $\vec{e}^{T}$ is the vector of independent random variables from the normal distribution $\mathrm{N}(0,1)$ and $P$ is the upper triangular matrix derived from the covariance matrix $C$. More details on modelling stochastic variables can be found in Clewlow (2000), Bunn (2004), Kaminski (2004), Zmeškal (2004) etc).

The relationship between the triangular matrix and the covariance matrix is as follows,

$$
C=P \cdot P^{T},
$$

where the upper triangular matrix is constructed on the basis of the following rules:

$$
\begin{array}{ll}
p_{i i}=\left(\sigma_{i i}-\sum_{k=1}^{i-1} p_{k i}^{2}\right)^{1 / 2} & \text { for } i=1,2, \ldots \ldots . . N, \\
p_{i j}=\left(\sigma_{i i}-\sum_{k=1}^{i-1} p_{k i} \cdot p_{k j}\right) \cdot p_{i i}^{-1} & \text { for } 1 \leq i<j \leq N, \\
p_{i j}=0 & \text { for } i>j ; \quad i, j=1,2, \ldots \ldots \ldots N .
\end{array}
$$

Parameters of the models for electricity prices and variable costs of productions were estimated by employing LSE methods and are summarised in the Table 3. 
Table 3: Model parameters (LSE method)

\begin{tabular}{|c|c|c|c|c|}
\hline & Annual drift rate & $\begin{array}{c}\text { Annual standard } \\
\text { deviation (\%) }\end{array}$ & Initial price (c.u.) & $\begin{array}{c}\text { Correlation of } \\
\text { residuals }\end{array}$ \\
\hline Electricity price & 0,136 & 12,24 & 42,69 & \multirow{2}{*}{0,194504} \\
\cline { 1 - 3 } $\begin{array}{c}\text { Variable costs of } \\
\text { production }\end{array}$ & 0,477 & 13,87 & 36,87 & \\
\hline
\end{tabular}

\subsection{Project valuation}

\subsubsection{Traditional NPV}

Project valuation is based on the criterion of traditional Net Present Value (NPV). This method relies on the comparison of the present value of cash flow generated by the project and investment outlays over the project life time, which can be mathematically written as follows,

$$
N P V=\sum_{t=0}^{N} \frac{F C F_{t}}{(1+R)^{t}},
$$

where $F C F$ is free cash flow generated by the project in a given year $t, N$ are expected years of operation and $R$ is cost of capital. If the NPV is positive, the investment should be accepted, otherwise it is better to reject it.

There are two basic forms of NPV calculation, which differs in the way, how the free cash flows are defined.

In this study, NPV version on the basis of equity capital is applied, where free cash flows are defined as cash flows for equity holders (investors), which are discounted by the cost of equity. In this case, general equation (15) has this form,

$$
N P V=\sum_{t=0}^{N} \frac{F C F E_{t}}{\left(1+R_{E}\right)^{t}},
$$

where $F C F E$ is free cash flow to equity (investors) and $R_{E}$ is cost of equity.

$F C F E$ in a given year of operation stage can be expressed as a difference between projected cash inflows and outflows, i.e.

$$
F C F E_{t}=E A T_{t}+D E P_{t}-I N V_{t}-\Delta W C_{t}+L_{t}^{+}-L_{t}^{-},
$$

where $E A T$ is net profit after taxation in a given year, $D E P$ is depreciation, $I N V$ is investment outlay, $\Delta W C$ is net change in working capital, $L_{t}^{+}$is investment bank credits accepted in a given year and $L_{t}^{-}$is credit instalments in a given year. Net profit after taxation generated by the project is defined this way, 


$$
E A T_{t}=\left(\operatorname{Re} v_{t}-C_{\mathrm{var}, t}-D E P_{t}-C_{f i x, t}-C_{f i n, t}\right) \cdot(1-d),
$$

Process of expected $N P V$ computation can be summarized into the following steps:

(i) Electricity price and operational costs modelling according to (10) - (14).

(ii) Free Cash Flows to Equity ( $F C F E$ ) calculation for each year and scenario according to (17) and (18).

(iii) Expected $N P V$ calculation for each path of $F C F E$ 's according to (16).

(iv) Expected $N P V$ density and distribution function constructing.

(v) VaR and Expected Shortfall calculation.

\subsubsection{Project valuation with individual real options}

As described above, it is supposed that management will be able to revise its operational strategy 5 years after project imitating. Due to the uncertainty in prices and variable costs of production, management can expand, contract, abandon or temporarily shut down the project (see Table 1 for more option details). Each option and its impact on project NPV is in this part valued in isolation, results are presented graphically by NPV density function and NPV distribution function, see Figure 1 and 2. Furthermore, statistical parameters of each NPV distribution including risk measures Value at Risk (VaR) and Expected Shortfall (ES) at $95 \%$ significance level are calculated, see Table 3. In the end, sensitivity analysis of VaR is analysed, see Figure 3. 
Figure 1: NPV density functions including individual real options

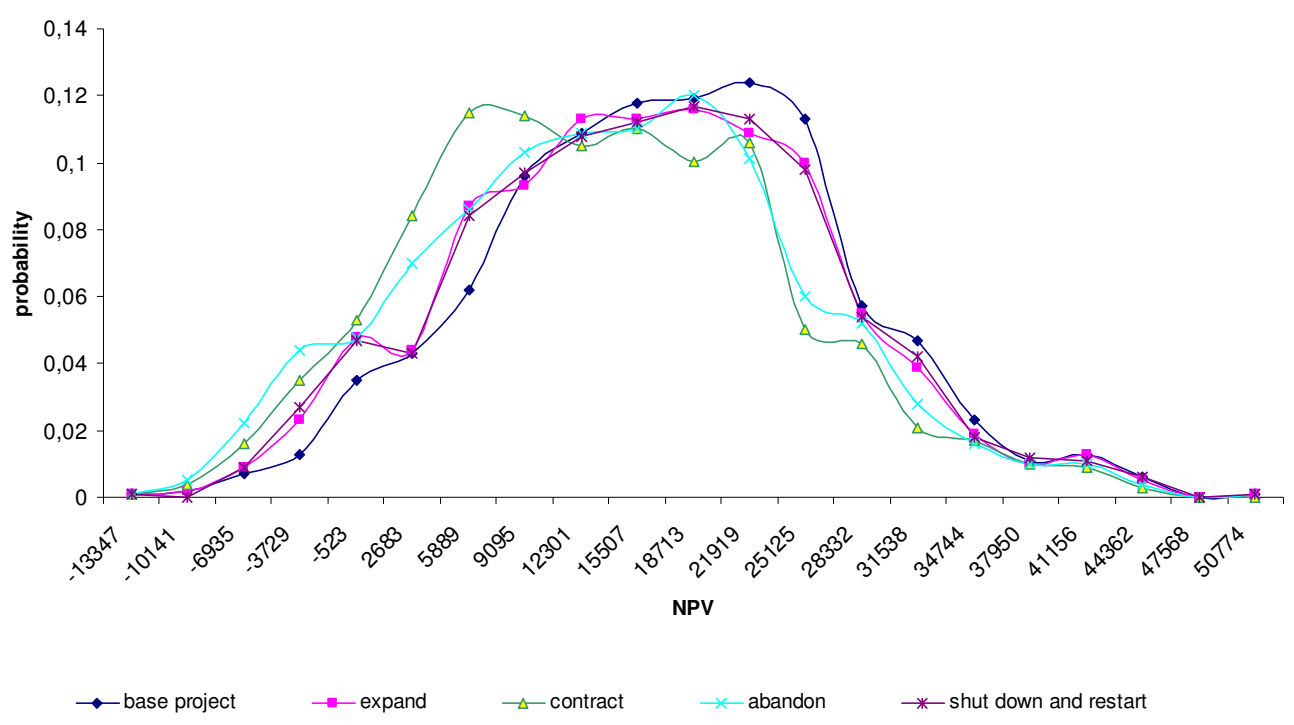

Figure 2: NPV distribution functions including individual real options

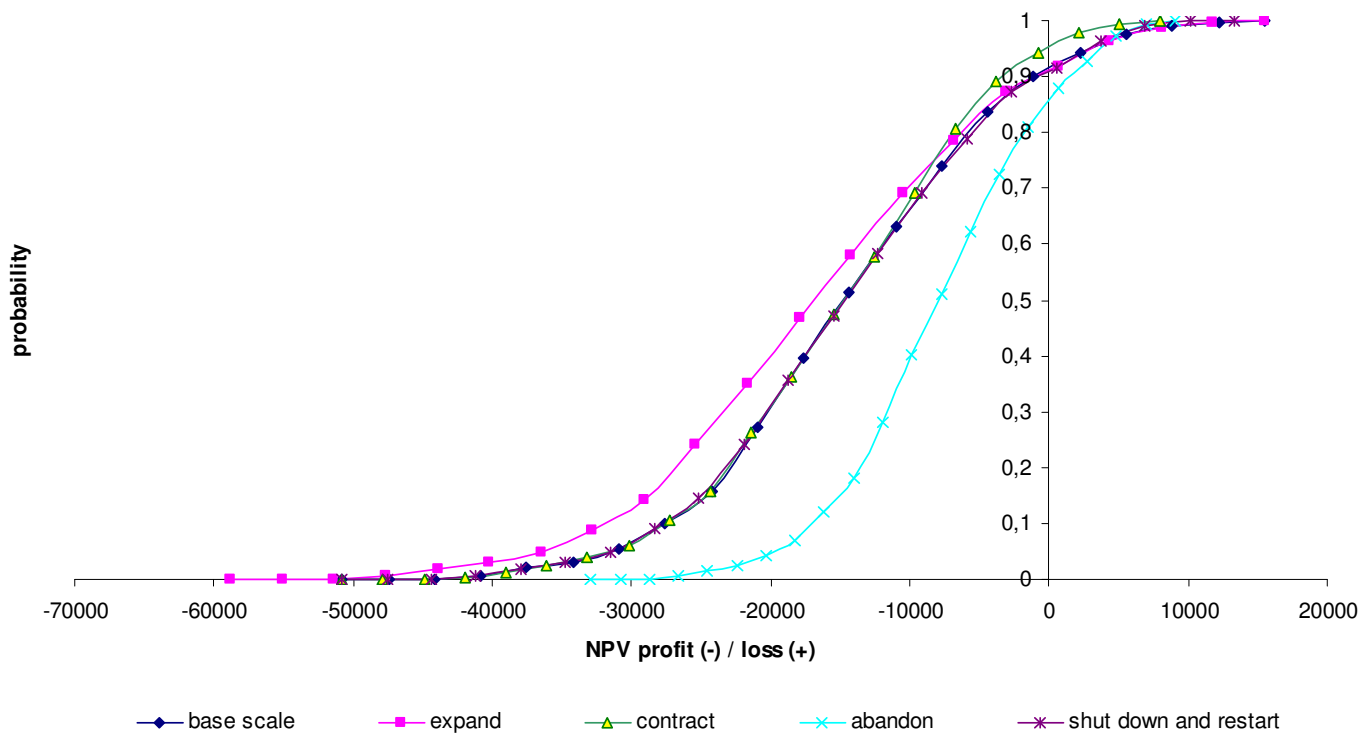


Table 3: Statistics of NPV distributions (individual real options)

\begin{tabular}{|c|l|r|r|r|r|r|r|r|}
\hline \multicolumn{2}{|c|}{} & \multicolumn{7}{|c|}{ NPV distribution criterion (c.u.) } \\
\cline { 3 - 9 } \multicolumn{2}{|c|}{} & \multicolumn{1}{|c|}{ min } & max & \multicolumn{1}{c|}{ mean } & \multicolumn{1}{c|}{ median } & \multicolumn{1}{c|}{ st. dev. } & \multicolumn{1}{c|}{ VaR } & ES \\
\hline \multicolumn{2}{|c|}{ NPV - base project } & -15492 & 50774 & 14565 & 14629 & 10386 & 3005 & 6140 \\
\hline \multirow{3}{*}{$\begin{array}{c}\text { NPV with } \\
\text { option }\end{array}$} & expand & -15492 & 58796 & 16801 & 16940 & 11931 & 3005 & 6140 \\
\cline { 2 - 9 } & contract & -7993 & 50774 & 15199 & 14629 & 9519 & -241 & 2098 \\
\cline { 2 - 9 } & abandon & -9045 & 32921 & 7925 & 7893 & 7021 & 3736 & 7021 \\
\cline { 2 - 9 } & shut down & -13347 & 50774 & 14592 & 14629 & 10316 & 3052 & 5487 \\
\hline
\end{tabular}

Figure 3: Value at Risk sensitivity analysis

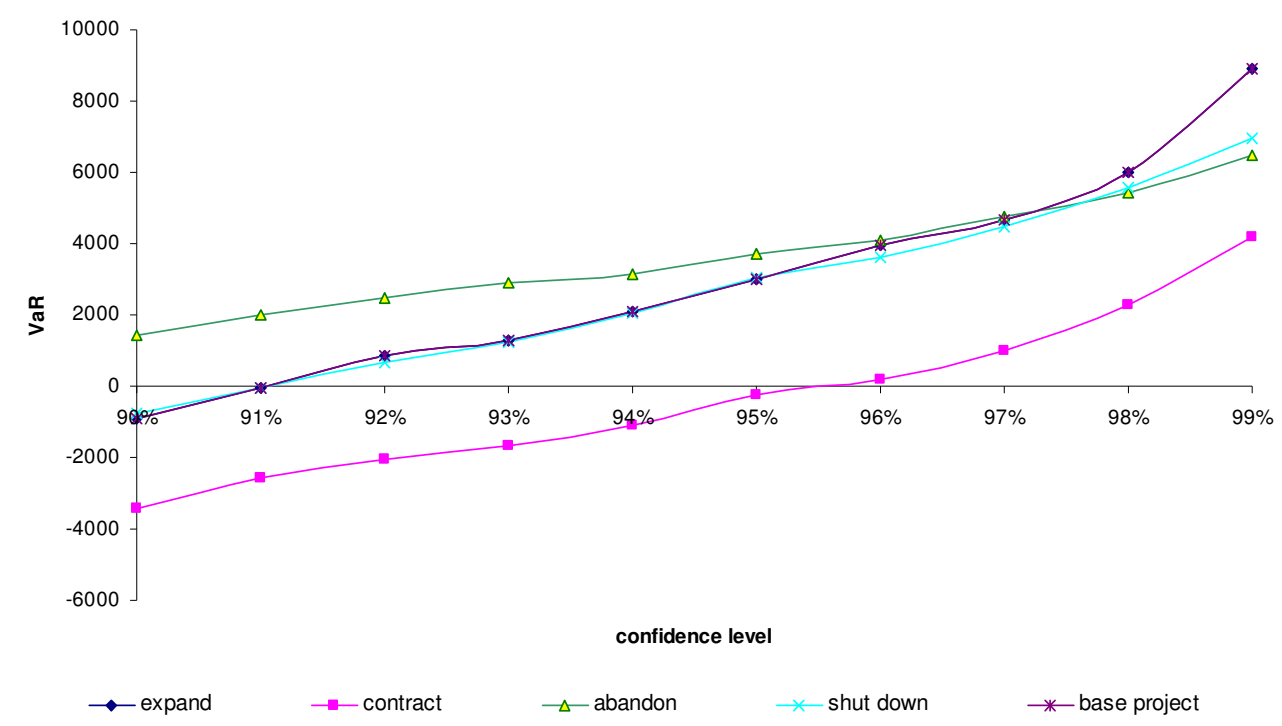

\subsubsection{Intrinsic value evolution of individual real options}

So far it was assumed that all the real options are options of European type. In the following analysis, we abandon this assumption and suppose, that the action can be undertaken whenever between $5^{\text {th }}$ year of operation phase and expected end of project life.

The aim of this analysis is to observe intrinsic value evolution with respect to the year of exercising. Furthemore, all the option parameters stay constant over the whole horizon (scale of expanding, contracting, resale project value, investment outlay on expanding, etc). Results are apparent from Figure 4. - 7 .

It is obvious, that in the case of certain options, the sooner exercised the higher intrinsic value (option to exercise), opposite results can be seen in the case of option to contract.

In the case of option to abandon the project, the closer to the end of the operating stage, the higher the frequency (or probability) the option will be exercised. 
Figure 4: Intrinsic value evolution in dependence on exercising (option to expand)

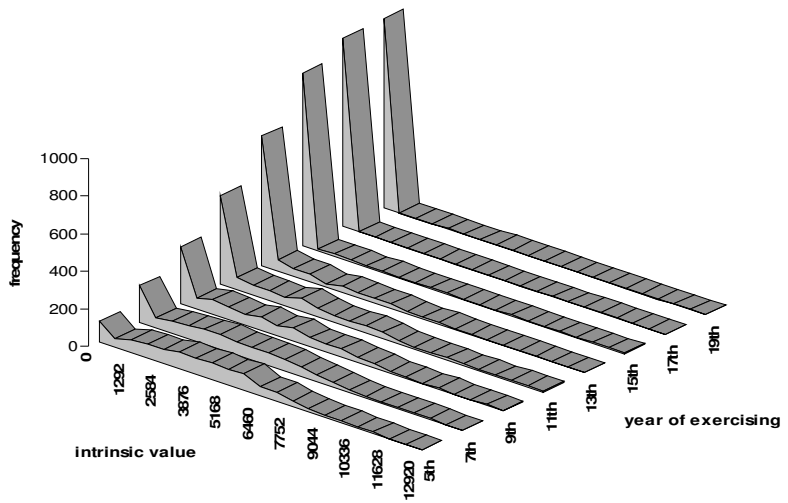

Figure 5: Intrinsic value evolution in dependence on exercising (option to contract)

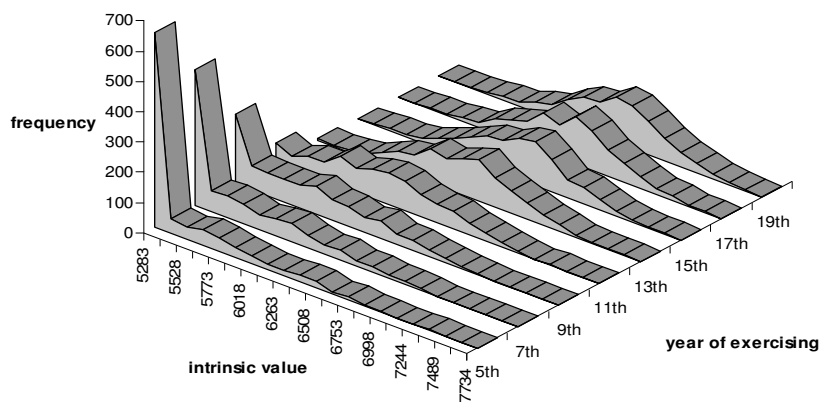

Figure 6: Intrinsic value evolution in dependence on exercising (option to abandon)

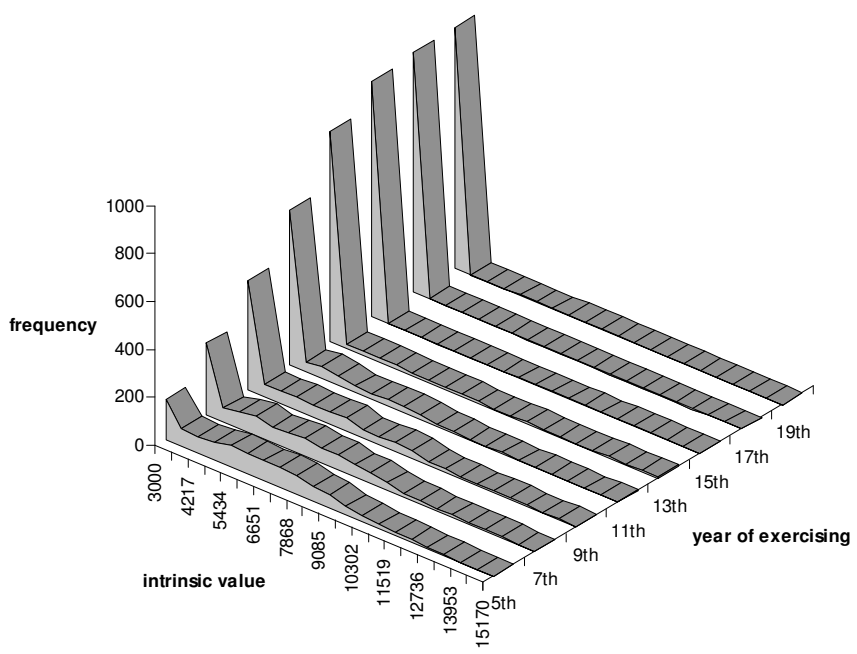


Figure 7: Intrinsic value evolution in dependence on exercising (option to shut down and restart)

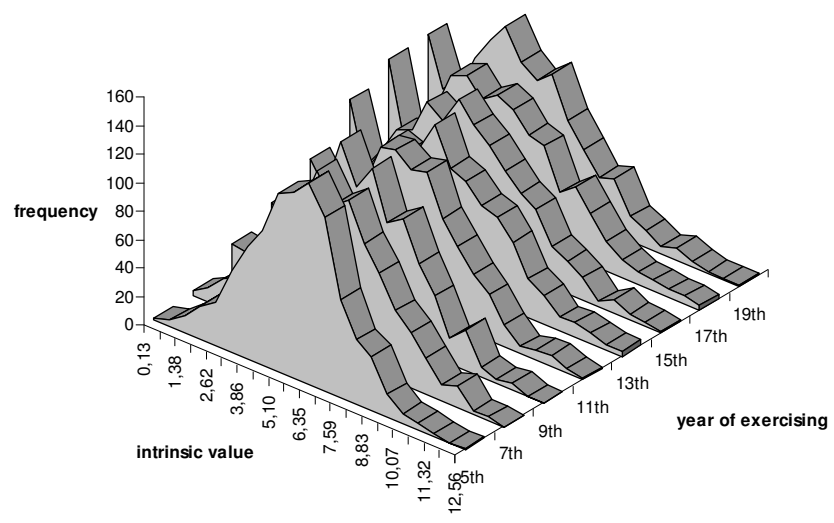

\subsubsection{Project valuation with multiple real options}

In the following part of the paper it is assumed, that management has the flexibility to revise its operational strategy; but instead of assuming only one type of operation option in year 5 after project initiating, more possible actions is assumed. More precisely, it is supposed that management has the flexibility to

- expand or abandon the project,

- expand or contract the project,

- contract or abandon the project,

- expand, contract or abandon the project.

Results of the calculation are summarized in the following Table 4 and graphically presented in Figure 4. 
Figure 8: NPV density functions with multiple real options

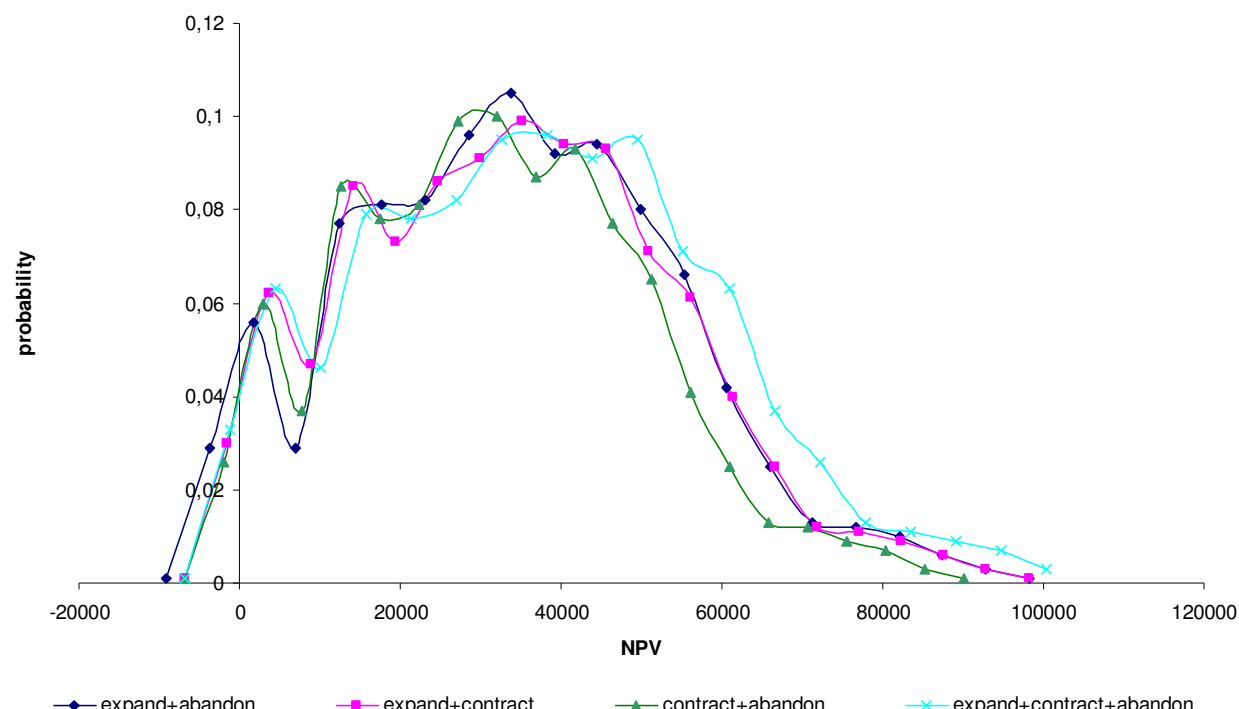

Figure 9: NPV distribution functions with multiple real options

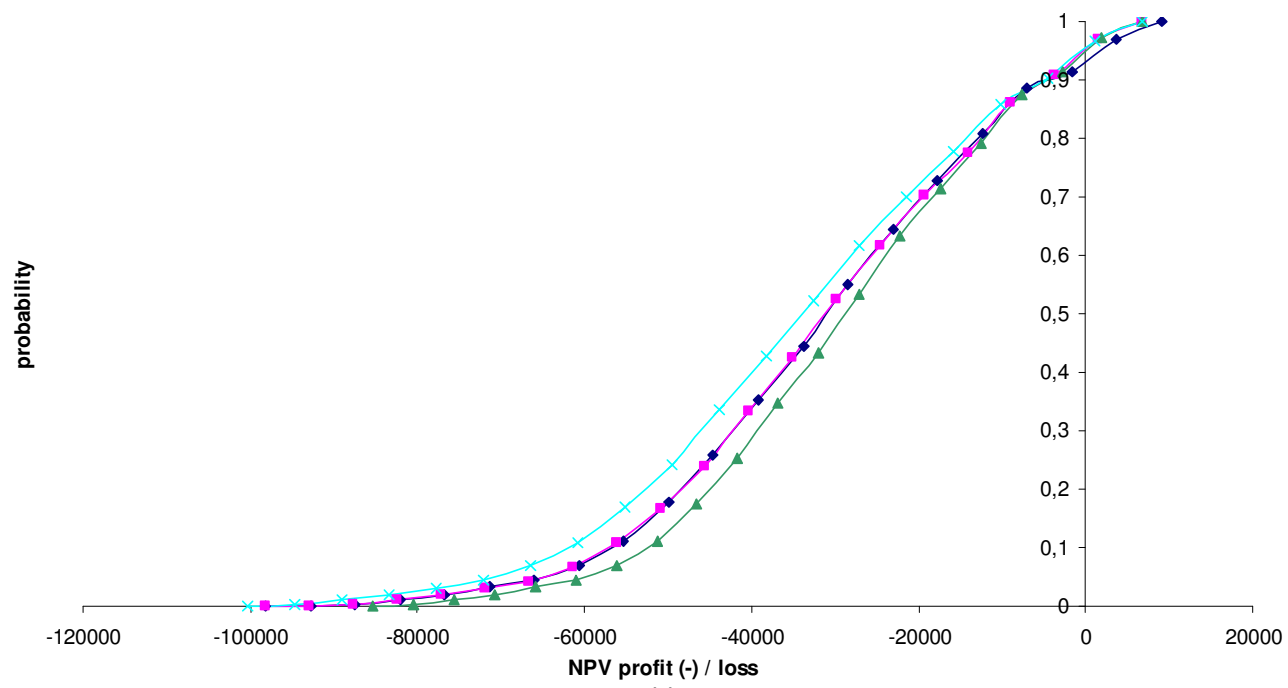

(+)

$\rightarrow$ expand+abandon $\rightarrow$ expand + contract $\rightarrow$ contract+abandon $\rightarrow$ expand + contract+abandon

Table 4: Statistics of NPV distributions (multiple real options)

\begin{tabular}{|l|r|r|r|r|r|r|r|}
\hline \multirow{2}{*}{} & \multicolumn{7}{|c|}{ NPV distribution criterion (c.u.) } \\
\cline { 2 - 9 } & \multicolumn{1}{|c|}{ min } & \multicolumn{1}{|c|}{ max } & \multicolumn{1}{c|}{ mean } & \multicolumn{1}{c|}{ median } & \multicolumn{1}{c|}{ st. dev. } & \multicolumn{1}{c|}{ VaR } & ES \\
\hline Expand + abandon & -9045 & 98158 & 31302 & 31302 & 20168 & 2207 & 4387 \\
\hline Expand + contract & -6833 & 98158 & 31302 & 31302 & 19893 & 50 & 2333 \\
\hline Contract + abandon & -6833 & 90136 & 29283 & 29047 & 18326 & 50 & 2333 \\
\hline Expand + contract + abandon & -6833 & 106031 & 34405 & 33907 & 21623 & 47 & 2328 \\
\hline
\end{tabular}


Figure 10: Value at Risk sensitivity analysis

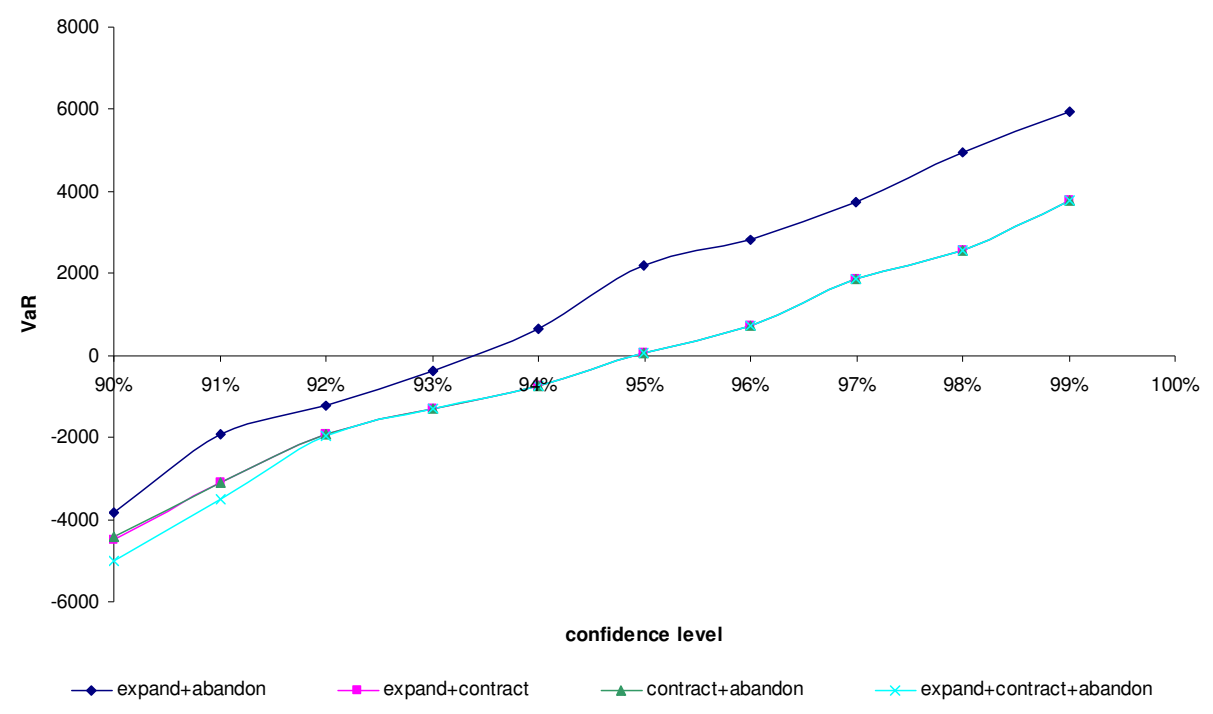

\subsubsection{Comment on results}

As it is apparent from the results in Table 3 and 4, presence of real options has a strong impact on NPV distribution statistics and risk measures.

It results from Table 3, that regardless what type of real option is assumed, its presence improve all the statistics and risk measures of NPV distribution.

In the case of option to expand, the potential profit has increased, whereas in the case of option to contract, abandon and shut down and restart, the probability of potential looses has decreased. These conclusions are confirmed by risk measures Value at Risk and Expected Shortfall. In the case of option to expand the project NPV will not be bellow -3005 c.u. (with 95 $\%$ probability, $\mathrm{VaR}=3005$ ); this result is equal to the potential loss without option (on the same confidence level). In the case of other options embedded are these potential looses lower. Even in the case of option to contract is VaR measure negative which means, that with probability $5 \%$ will not drop the project NPV below 241 c.u.

Similar conclusions are apparent from Table 4. All the combinations of assumed real options increase expected NPV of the project, minimize potential looses and increase maximal potential profit. Moreover, there was here confirmed, that real options present in combination generally make the individual values nonadiditive. 


\section{Conclusion}

The aim of this study was to analyze the flexibility of the management decision-making on project value in electricity generation sector. The flexibility is reflected in real options - possible actions, which can be undertaken by management as a reaction on changes in market conditions. These changes can have a strong impact on the project value and that is why must be added to the total project value. They can maximize the project profitability or minimize the possible looses.

In this study, NPV criterion on the basis of simulation approach was applied. We supposed that electricity prices and operational costs are not only stochastic variables, but also are correlated. For that reason, for their modelling, Cholesky algorithm was applied.

We supposed that there were four different real options analyzed and valued: option to expand, contract, abandon and shut down and restart a project. First, traditional passive approach (i.e. without options) was assumed, next, selected options were valued and their impact on project NPV was analyzed. In the end, selected portfolios of real options were valued and compared, distribution characteristics were compared and analyzed.

It is apparent from the results and their graphical presentations, that real option have a strong impact on project value. Type of the real option and the timing of its exercising are the main factors. As result from figures, some options (here option to expand) increases the possible profit, whereas other options (contract, abandon, temporarily shut down and restart) minimize the possible losses, if the market conditions evolve less favourably. These conclusions are confirmed by the Value at Risk or Expected Shortfall results, see Table 3.

In the Chapter 3.4.3 evolution of the intrinsic value with respect to the time of exercising was studied. It is obvious from the results and it confirms general rules that under the assumption that all the variables stay constant, the intrinsic value increase may decrease (option to expand), increase (option to contract or abandon), or may evolve stochastically according to the prevailing market conditions - here prices of input and output(option to shut down and restart).

In the last part of the paper, selected combinations of real options were valued and compared with their individual values. Three different combinations of two options and one combination of three options were examined. All the observed statistic and risk measures of NPV distributions have improved; moreover the nonadditivity of real options was confirmed. 


\section{Aknowledgement}

This paper is written within the research project No. 402/07/P121 and supported by GAČR (Czech Science Foundation). This support is greatly acknowledged.

\section{REFERENCES}

[1] AMRAM, M., KULATILAKA, N.: Real Options: managing strategic investments in an uncertain world. Harvard Business School Press, Boston, 1999.

[2] BRENNAN, M.J., TRIGEORGIS, L.: Project Flexibility, Agency and Competition: new developments in the theory and application of Real Options. Oxford University Press, London, 2000.

[3] COPELAND, T.E., ANTIKAROV, V.: Real Options: practitioner's guide. Texere, New York, 2000.

[4] DLUHOŠOVÁ, D. et al.: Aplikace metodologie reálných opcí ve finančním rozhodování. VŠB-TU Ostrava, 2006.

[5] DLUHOŠOVÁ, D.: Finanční řízení a rozhodování. VŠB-TU Ostrava, 2007.

[6] DIXIT, A.K., PINDYCK, R.S.: Investment under Uncertainty. University Press, 1994.

[7] DOWD, K.: Measuring market risk. Wiley. 2005.

[8] HOWEL, S. et al.: Real options. Evaluating Corporate Investment Opportunities in a Dynamic World. Prentice Hall, London, 2001.

[9] HULL, J.C. Option, futures and other derivatives. $5^{\text {th }}$ edition. Prentice Hall, USA, 2002.

[10] JORION, P.: Value at Risk. McGraw-Hill. 2000.

[11] MUN, J.: Real Option Analysis. Tool and Techniques for Valuing Strategic Investments and Decisions. John Wiley and Sons, Inc., New Jersey, USA, 2002.

[12] MUN, J.: Real Options Analysis Course: Business Cases and Software Applications. Wiley, 2003.

[13] MUN, J.: Real Options Analysis: Tools and Techniques for Valuing Strategic Investment and Decisions, 2nd Edition. Wiley; 2005.

[14] MUN, J.: Modeling Risk: Applying Monte Carlo Simulation, Real Options Analysis, Forecasting, and Optimization Techniques. Wiley, 2006. 
[15] SHOCKLEY, R.L.: An Applied Course in Real Options Valuation. South-Western College Pub; 1 edition, 2006.

[16] TRIGEORGIS, L., SMITH, H., T., J.: Strategic Investment: Real Options and Games. Princeton University Press, 2004.

[17] TRIGEORGIS, L.: Real Options in Capital Investments: models, strategies and applications. Praeger, Westport, 2000.

[18] TRIGEORGIS, L.: Real Options: managerial flexibility and strategy in resource allocation. The MIT Press, Cambridge, 1998.

[19] TRIGEORGIS, L., SCHWARTZ, E.S.: Real Options and Investments under Uncertainty. The MIT Press, Cambridge, 2001.

[20] VOLLERT, A.: A Stochastic Control Framework for Real Options in Strategic valuation. McKinsey Comp., Boston, 2003.

[21] ZMEŠKAL, Z. et al.: Financial models. EkF VŠB-TU Ostrava. 2004. 